\title{
EVALUATING THE EFFICIENCY OF THE SYNERGISTIC EFFECT IN THE BUSINESS NETWORK
}

\author{
Valeriia Dykan, Oleksandr Pakharenko \\ V. N. Karazin Kharkiv National University, Kharkiv, Ukraine \\ Volodymyr Saienko, Andrii Skomorovskyi \\ Academy of Management and Administration, Opole, Poland \\ Tetiana Neskuba \\ Ukrainian State University of Railway Transport, Kharkiv, Ukraine
}

\begin{abstract}
This article aims to develop a methodology for monitoring the quality of the synergistic effect of enterprises' economic activity in business networks for mechanical engineering in Ukraine. Using the expert assessments of 386 senior and middle managers of 27 mechanical engineering enterprises of the Kharkiv region and the main components' method, the components of qualitative parameters of the synergetic effect of economic activity that result from network interaction have been determined. An additive econometric model has been developed to calculate the integrated indicators of the enterprises' economic activity's synergetic effects in terms of the business networks of the studied enterprises. By constructing nonlinear regression models, the integrated synergy indicator of each enterprise's profitability was characterized with respect to the effectiveness of the network interaction's feasibility. The obtained results will help develop enterprise development strategic directions for constant monitoring of the feasibility of business network interaction.
\end{abstract}

Keywords: Ukraine, business network, quasi-integration relations, economic activity, synergistic effect, enterprise

DOI: http://dx.doi.org/10.15549/jeecar.v8i1.646

\section{INTRODUCTION}

The transformation of forms of business organization in Ukraine and the gradual transition to network forms of business organization is an evolutionary step. Due to the risks involved in moving from industrial-based to information-based economic development, businesses are looking for new structures that will provide competitive advantages (Brunet Thornton, Cramer \& Jirsák, 2019). In Ukraine, it is the process of business networking, the formation of quasi-integration links, and the development of network organizational 
structures that help solve the problem of finding a rational organizational partnership and combining several business organizations' entrepreneurial efforts by using new methods adapting to constant environmental changes.

The need to and advantages from doing business through the networking of enterprises is primarily a synergistic effect of market competitiveness (Rzepka, 2017), which gradually creates a long-term competitive advantage, the basic element of which is the ability of networked enterprises to implement their self-development function (Zadorozhna, 2014).

In this sense, in the context of the acute economic crisis caused by the spread of the COVID-19 pandemic, which provoked mass bankruptcies in the SME sector (Megits, Neskorodieva \& Schuster, 2020), the organization of business activities through the business networking of economic ties enables small businesses to combine advantages of small forms of entrepreneurship with the scale of a large manufacturer to develop business and increase profitability.

Improving Ukraine's ability to develop business networking in one of of the government's key tasks, defined by the Decree of the President of Ukraine of November 8, 2019, № 837 “On urgent measures for reforms and strengthening the state" (2019). Today, though, the formation of business network structures has not become widespread due first of all to the lack of an appropriate regulatory framework for regulating business networks' activities or maintaining official statistics on their number and results of economic activity.

The direct lack of a methodological framework that would allow companies to assess the qualitative and quantitative parameters of the synergetic effect of network partners and the feasibility of developing quasi-integration links at this stage of business development is also a negative impact. The enterprises-participants of the business networks are independent business entities, each of which is focused on the performance of its tasks, which correlate with the network's business objectives and the achievement of the network's overall effect by maximizing the efficiency of each of its members. That the analyzed networks include enterprises of different sectors of the economy and located in different Ukraine regions also is confirmation of the need to assess the effectiveness at the level of each of the enterprises participating in the business network. Therefore, this study aims to develop a methodological approach to identify qualitative parameters of the synergistic effect of enterprises' economic activity in the process of network interaction to constantly monitor the feasibility of business network partnerships and improve quasi-iterative business relationships.

\section{LITERATURE REVIEW}

Based on the analysis of approaches to interpreting the structure of network economic content, it can be argued that they are closely related but do not provide a comprehensive description and focus on a certain stage of development or functional features between business relationships. Thus, at the first stage of network development, the interaction between enterprises may be short-term. In the second stage, relations become more stable and longlasting based on enterprises' joint coordination and cooperation (Abbas et al., 2019). The topology of connections becomes more complex, and enterprises' interdependence closer (based on the integration of interests and goals). Finally, in the third stage, the network structure is formed as an institution with established operation rules (Chen, Lei \& Hsu, 2019). Therefore, the network structure will be understood as a hybrid form of interaction of business structures that operate based on quasiintegration forms of management to achieve a synergistic effect in realizing common economic interests.

As evidenced by the analysis of the scientific literature in the development of the methodological apparatus for assessing the synergistic effect of network interaction in economic research, two scientific approaches are used (Mainali et al., 2018; Fang et al., 2020; Fiorentino \& Garzella, 2015; Zhang et al., 2018).

The first approach (Mainali et al., 2018; Fang et al., 2020) is based on comparing enterprise performance indicators (primarily profitability indicators) to participate in business network associations and the emergence of quasiintegration links within the framework of 
connections. The disadvantage of this approach, in our opinion, is that changes in the economic efficiency of enterprises may be due to qualitative changes in the enterprise, not related to network interaction (e.g., technological changes, changes in approaches to personnel management, etc.). Besides, there are often cases when the company is a partner of more than one business structure. In this case, this approach does not differentiate and make an economic assessment of the synergetic effect of the partnership network interaction. As for the assessment of the synergetic effect based on the dynamics of transaction costs, in practice, it is completely impossible due to the lack of relevant information in the public domain and is subject to some doubts about its confidentiality (Shtal, Hurzhii \& Bresciani, 2016).

Entrepreneurial network structures are mostly open structures, which are usually open for joining new business units, reflecting the content and basis of the functioning of this type of business organization (Szromek, 2020). But the main guarantee and condition for the establishment and development of business networks is the compatibility and consistency of the purpose of all business units, or business partners, of the network. Therefore, the second approach to assessing the synergistic effect of network interaction (Fiorentino \& Garzella, 2015; Zhang et al., 2018) is based on qualitative assessment, which avoids the shortcomings of quantitative parameters (Fiorentino \& Garzella, 2015; Zhang et al., 2018). Existing qualitative methods for assessing business network interaction's synergetic effects did not provide for the calculation of an integrated indicator (Fiorentino \& Garzella, 2015; Zhang et al., 2018) and qualitative assessment of synergy levels. The lack of an integrated indicator and its levels significantly complicates network management's decision-making process. The synergy effect is based on a significant number of qualitative characteristics that have different levels and different dynamics.

Besides, studies such as Fiorentino \& Garzella (2015) do not identify the structural components of the synergistic effect, which does not allow the identification of strengths and weaknesses in the management of network interaction. Or such components are not statistically confirmed.

\section{METHODOLOGY}

The study's methodological basis is expert evaluation, main components, and regression analysis. The use of the expert method is due to the need to obtain quantitative estimates of the synergetic effect based on the characteristics of the effectiveness of the management of quasiintegration relations, which are not reflected in the official reporting forms of enterprises; there are no statistics. The disadvantage of the expert method is the evaluation results' subjectivity (Fiorentino \& Garzella, 2015). Still, this shortcoming can be offset using a sufficient number of experts within this study and taking into account their representative characteristics (age, experience, functions in the enterprise, attitudes) management).

The survey was completed by $10-15$ representatives - senior and middle managers from each company, which formed the study's basis. The total number of respondents with feedback and questionnaires received was 386 people: $39.9 \%$ senior managers and 60.1\% middle managers. The number of respondents indicates the sample's representativeness at a significance level of $p=0.05$. The survey was conducted remotely using the Google Form during May-December 2019. The survey was voluntary and anonymous.

Machine-building enterprises formed the study sample - members of associations, concerns, corporations, business groups, which are characterized by legal independence and registered in the Kharkiv region (Ukraine). These are 27 enterprises that are part of the State Concern, "Ukroboronprom", the business group DCH, the association "Ukrelectrokabel", the industrial group "Ukrainian Industrial Energy Company", the corporation "Ukrinmash," the industrial and financial corporation "MastIpra," and the company "DTEK Energo". The choice of the machine-building industry is due to its high scientific, intellectual, innovative and capital intensity among other industries in Ukraine and the world (National Science Foundation, 2018). This industry requires a concentration of skilled labor, significant financial and high-tech production resources 
which can be most effectively implemented through effective networking and the development of quasi-iterative links.

During the survey, respondents were asked to evaluate the questionnaire's statements (Questionnaire to determine the qualitative components of the synergistic effect of economic activity of enterprises for business interaction networks, 2019) relating to certain areas of entrepreneurial activity of the network interaction of the enterprise which the respondent represents. The questionnaire was formed from statements that characterize management functions' effectiveness (planning, organization, motivation, control) in network interaction, the degree of effectiveness of which depends on the level of synergy.

The respondents evaluated the questions of the questionnaire on a 4-point Likert scale with the answer options "I completely disagree," "I do not agree," "I agree," "I completely agree" (Lipovetsky, 2017). This toolkit is widely used in various science fields, as Likert scales allow you to create a set of data that provides an understanding of respondents' views. These data have quantitative characteristics so that they can be easily analyzed statistically.

Compared to the scoring system, operating with the qualitative categories "agree" / "disagree" has simplified the grading of respondents who are not a specially trained group of experts.

When processing the results, the respondents' answers to the questionnaire questions were translated into points. The answer "completely disagree" was given "1" point, "disagree" - "2" points, "agree" - "3" points, "completely agree" "4" points (Lipovetsky, 2017). The questionnaire's reliability was confirmed by the value of the Cronbach's alpha coefficient, using the software product Statistica 12.0.

To determine the components of the synergetic effect of economic activity, the principal components method was used. Variables for the analysis were scores on the questionnaire. The number of observations corresponds to the number of completed questionnaires $(\mathrm{N}=386)$. To establish the optimal number of factors (main components), Kaiser's criterion was used, according to which factors with eigenvalues $\geq 1.0$ are significant
(Menke, 2018). The establishment of the type of synergetic effect was carried out based on variables (questionnaire questions), which, following the factor loads, formed the corresponding factor. Factor loads $\geq|0.7|$ are considered significant (Menke, 2018).

The calculation of factor values for the analytical assessment of the synergetic effect of economic activity in terms of business network interaction based on qualitative parameters of management efficiency was carried out in Statistica 12.0 based on scores on questions 1 through 50. These estimates were calculated as the arithmetic mean of the estimates of respondents representing one enterprise. The calculation of average values was possible because the coefficient of variation of assessments of respondents/representatives of one enterprise did not exceed 3.4\%. The factors' values have been calculated as the sum of the indicators' normalized values adjusted for factor loads. The values of the factors were calculated because they do not have lower and upper limitations, which complicates the results' interpretation. With this in mind, the study sample was supplemented by two observations: one with the minimum values of all indicators ("1" point), the other with the maximum ("4" points), and identified a range of possible values of network interaction management efficiency factors. To qualitatively explain the levels of the synergistic effect, the Fibonacci rule was used, according to which the range of factor values is divided into 3 intervals by Adam, Assimakis \& Farina's (2015) formula:

$$
\left\{\begin{array}{l}
F_{i 1}=F_{i \text { min }}+0.38\left(F_{i \text { max }}-F_{i \text { min }}\right) \\
F_{i 2}=F_{\text {imin }}+0.62\left(F_{i \text { max }}-F_{i \text { min }}\right)
\end{array}\right.
$$

Where $F_{i \min }$ is the minimum possible value of the i-th factor (components of the synergistic effect);

$F_{i \text { max }}$ is the maximum possible value of the ith factor;

$F_{i 1}$ is the value of the factor corresponding to the upper limit of the lower level;

$F_{i 2}$ is the value of the factor corresponding to the upper limit of the average level;

$\left[F_{i \text { min }} ; F_{i 1}\right]$ is the range of values of the low level of the i-th factor; 
$\left(F_{i 1} ; F_{i 2}\right]$ is the range of values of the average level of the i-th factor;

$\left(F_{i 2} ; F_{i \text { max }}\right]$ is the range of values of the high level of the i-th factor.

Based on the calculated values of factors, the integral indicator of synergetic effect of economic activity based on qualitative characteristics of efficiency of management of network interaction at the enterprise for which formula (2) was used is defined:

$$
I S=\sum F_{i} \times d_{i},
$$

де $I S$ is the integrated indicator of the synergetic effect of business network interaction management;

$F i$ is the value of the i-th component of the synergistic effect;

$d i$ is the value of the variance (shares) of the ith component.
Nonlinear regression models were used to assess the impact of the integrated synergy indicator on the enterprise's efficiency. The software product Statistica 12.0 simulated the impact of the integrated indicator of the synergistic effect of network interaction management (independent variable) on the profitability of the enterprise as the main indicator of efficiency (Khurana et al., 2021), the dependent variable. The influence on the enterprise's profitability for the corresponding period and with a lag of 1 year was investigated. The number of observations corresponds to the number of sample enterprises (27).

\section{RESULTS}

To assess the questionnaire's reliability based on respondents' scores, the values of the Cronbach's alpha coefficient have been calculated (Table 1).

Table 1: Reliability indicators of the questionnaire for evaluating the effectiveness of business network interaction management of machine-building enterprises in the Kharkiv region

\begin{tabular}{|c|c|c|c|c|c|}
\hline $\begin{array}{c}\text { Statements } \\
\text { in the } \\
\text { questionnaire }\end{array}$ & $\begin{array}{c}\text { Cronbach's } \\
\text { alpha value }\end{array}$ & $\begin{array}{c}\text { Statements } \\
\text { in the } \\
\text { questionnaire }\end{array}$ & $\begin{array}{c}\text { Cronbach's } \\
\text { alpha value }\end{array}$ & $\begin{array}{c}\text { Statements in } \\
\text { the } \\
\text { questionnaire }\end{array}$ & $\begin{array}{c}\text { Cronbach's } \\
\text { alpha value }\end{array}$ \\
\hline Q1 & 0.87 & Q18 & 0.87 & Q35 & 0.87 \\
\hline Q2 & 0.85 & Q19 & 0.89 & Q36 & 0.89 \\
\hline Q3 & 0.89 & Q20 & 0.87 & Q37 & 0.88 \\
\hline Q4 & 0.89 & Q21 & 0.89 & Q38 & 0.86 \\
\hline Q5 & 0.94 & Q22 & 0.89 & Q39 & 0.89 \\
\hline Q6 & 0.93 & Q23 & 0.89 & Q40 & 0.89 \\
\hline Q7 & 0.87 & Q24 & 0.89 & Q41 & 0.87 \\
\hline Q8 & 0.89 & Q25 & 0.87 & Q42 & 0.90 \\
\hline Q1 & 0.89 & Q26 & 0.89 & Q43 & 0.87 \\
\hline Q10 & 0.89 & Q27 & 0.89 & Q44 & 0.89 \\
\hline Q12 & 0.89 & Q28 & 0.89 & Q45 & 0.87 \\
\hline Q13 & 0.87 & Q29 & 0.89 & Q46 & 0.89 \\
\hline Q14 & 0.89 & Q30 & 0.87 & Q47 & 0.87 \\
\hline Q15 & 0.92 & Q31 & 0.89 & Q48 & 0.89 \\
\hline Q16 & 0.89 & Q32 & 0.86 & Q49 & 0.89 \\
\hline Q17 & 0.82 & Q33 & 0.89 & Q50 & 0.87 \\
\hline & & Q34 & 0.87 & Total & 0.89 \\
\hline
\end{tabular}

The value of the general Cronbach alpha coefficient was 0.89 , which corresponds to the boundaries of the standard value of 0.7-0.9 (Hair et al., 2017), and therefore indicates the reliability of the questionnaire. The value of
Cronbach's alpha for Q5, Q6, Q14, Q16, Q42 exceeded the average for the questionnaire. The exclusion of these questions from the questionnaire would lead to greater consistency, but, on the other hand, would narrow the 
studied problem. Since the Cronbach alpha coefficient's value for all questionnaire statements significantly exceeded the threshold value, the exclusion of Q5, Q6, Q14, Q16, and Q42 was inappropriate. The proposed questionnaire is consistent and suitable for further processing.

The respondents' answers have been structured using the main components' method, and the structural components of the synergetic effect were determined. According to Kaiser's criterion, 6 factors have been identified that characterize the effectiveness of network interaction management of enterprises and the possibility of obtaining a synergetic effect. Statistical characteristics of the factors are given in Table. 2.

Table 2: Statistical characteristics of factors - components of the synergetic effect of economic activity in the management of business network interaction of machine-building enterprises in the Kharkiv region

\begin{tabular}{|c|c|c|}
\hline Components & $\begin{array}{c}\text { Statements for the } \\
\text { questionnaire to evaluate the } \\
\text { component }\end{array}$ & $\begin{array}{c}\text { \% of component } \\
\text { dispersion }\end{array}$ \\
\hline The synergy of strategic management & $\begin{array}{c}\text { Q1-Q8, Q10-Q12, Q15-Q18, } \\
\text { Q22, Q27-Q32, Q44, Q45, Q47, } \\
\text { Q48, Q50 }\end{array}$ & 48.57 \\
\hline The synergy of labor potential management & Q13, Q21, Q37-Q43, Q46, Q49 & 18.72 \\
\hline Innovation and technological synergy & Q14, Q23, Q25, Q26 & 6.91 \\
\hline Information and communication synergy & Q9, Q19, Q20 & 4.30 \\
\hline Ecological synergy & Q24, Q33, Q34 & 4.23 \\
\hline Social synergy & $\mathrm{Q} 35, \mathrm{Q} 36$ & 3.81 \\
\hline
\end{tabular}

The cumulative percentage of the selected components' variance was $86.53 \%$, with a sufficient $80 \%$ to ensure the representativeness of the analysis (Menke, 2018).

The synergy of strategic management has been formed from the indicators characterizing the efficiency of planning, the organization, and control over observance of quasi-integration communications' basic principles. In general, they concern the definition of the network structure's strategic goal and the formation of tactical goals of network interaction, focusing on all network members while ensuring their independence and mutually beneficial conditions of cooperation. The variance of the factor was $48.57 \%$ and is the highest compared to other factors. From this, we can conclude that the effectiveness of quasi-integration relations' strategic management plays the most important role in ensuring the synergetic effect of network interaction of enterprises. The use of network interaction advantages is possible when the network participants are oriented towards common goals, regulation, and coordination of relations between the participants provided an effective system of dispute resolution and rational control.

The second most influential factor is the synergy of labor potential management. The variance of the factor was $18.72 \%$. The indicators that formed the factor assess the possibility of creating a positive effect of network interaction by avoiding duplication of personnel functions, professional development resulting from network interaction, increasing interest and satisfaction with the performance of their duties.

The factor of innovation and technological synergy has been formed from indicators that characterize the possibility of reducing the time of development and implementation of innovations in the enterprise, reducing 
enterprise costs for research, use of intellectual and other intangible resources, increasing the level of innovation and updating the technological base as a result of network interaction. The variance of the factor was $6.91 \%$.

The factor of information and communication synergy determines the effectiveness of the organization of information exchange between participants. There are no delays that could lead to negative consequences for the enterprise and the network. A factor of $4.30 \%$ characterizes the effectiveness of network interaction management.

The factor of ecological synergy characterizes the prospects of increasing energy efficiency of production, reducing emissions of exhaust gases into the atmosphere, thermal emissions, noise levels and reducing the level of electromagnetic pollution. The factor of social synergy determines the possibilities of expanding jobs and raising wages due to a business network of relations. As machine-building enterprises are not ecologically and socially oriented enterprises, the value of these synergy types is estimated at $8.04 \%$ in total, with a cumulative percentage of the variance of all selected factors of $86.53 \%$.

Positive values of factor loads for all indicators showed the stimulating nature of their impact on obtaining a synergistic effect of economic activity: an increase in the evaluation of indicators leads to increased efficiency of business network interaction management and the possibility of obtaining a positive synergistic effect.

The ranges of values of the levels of the components of the synergetic effect of the economic activity of the studied enterprises, determined by the Fibonacci rule (formula 1), are given in Table. 3 .

Table 3: Ranges of values of levels of components of synergetic effect of economic activity of business network interaction of machine-building enterprises in the Kharkiv region

\begin{tabular}{|c|c|c|c|c|}
\hline \multirow{2}{*}{ Components } & Range of possible & \multicolumn{3}{|c|}{ Ranges of values by levels } \\
\cline { 3 - 5 } & values & Low & Medium & High \\
\hline $\begin{array}{c}\text { The synergy of strategic } \\
\text { management }\end{array}$ & {$[0.87 ; 3.91]$} & {$[0.87 ; 2.03]$} & $(2.03 ; 2.75]$ & $(2.75 ; 3.91]$ \\
\hline $\begin{array}{c}\text { The synergy of labor } \\
\text { potential management }\end{array}$ & {$[1.01 ; 4.05]$} & {$[1.01 ; 2.17]$} & $(2.17 ; 2.89]$ & $(2.89 ; 4.05]$ \\
\hline $\begin{array}{c}\text { Innovation and } \\
\text { technological synergy }\end{array}$ & {$[0.94 ; 3.96]$} & {$[0.94 ; 2.09]$} & $(2.09 ; 2.81]$ & $(2.81 ; 3.96]$ \\
\hline $\begin{array}{c}\text { Information and } \\
\text { communication synergy }\end{array}$ & {$[0.76 ; 3.88]$} & {$[0.76 ; 1.95]$} & $(1.95 ; 2.69]$ & $(2.69 ; 3.88]$ \\
\hline Ecological synergy & {$[0.86 ; 3.90]$} & {$[0.86 ; 2.02]$} & $(2.02 ; 2.74]$ & $(2.74 ; 3.90]$ \\
\hline Social synergy & {$[0.98 ; 3.99]$} & {$[0.98 ; 2.12]$} & $(2.12 ; 2.85]$ & $(2.85 ; 3.99]$ \\
\hline
\end{tabular}

The results of the analysis of the sample of enterprises showed that the weaknesses in the management of business network interaction are: management of labor potential (the corresponding synergetic effect for $48.15 \%$ of enterprises was estimated at a low level); inefficiency of management of ecological and social component of economic activity of enterprises.
A positive aspect was the general acquaintance of all enterprises/participants of the business network associated with its activity principles, strategy, and adjustment of its own goals, growth of trust of clients, partners and investors to the enterprise due to network interaction.

The high level of synergetic effect of economic activity of network interaction was 
demonstrated by PJSC "Kharkiv Tractor Plant", SE "Chuguev Aircraft Repair Plant"and PJSC "Yuzhcable works", for which the synergy of strategic management, innovation-technological synergy, synergy of labor potential management (except for SE "Chuguev Aircraft Repair Plant") and information -communication synergy (except for PJSC "Kharkiv Tractor Plant"). The values of other factors are at an average level.

For other enterprises, the synergetic effect of economic activity of network interaction is on an average (55.56\% of enterprises) and low (33.33\%) level. On the one hand, this indicates an inefficient management system of quasiintegration relations. On the other hand, it is a reserve for obtaining a positive synergetic effect by increasing the management system's efficiency.
The calculated indicator of the synergetic effect is a synthetic indicator that complicates the economic interpretation. Therefore, regression models of the influence of the integrated indicator of synergy on enterprises' efficiency (through the indicator of profitability) are built. Because the survey, which was based on the integrated synergy indicator that was calculated, was conducted in 2019, the maximum possible lag in the study of the impact of the synergetic effect on the enterprise's profitability is 1 year. The model of the influence of synergetic effect on the profitability of the enterprise without time lag $\left(R_{n}=f\left(I S_{n}\right)\right)$ and with lag in 1 year $\left(R_{n}=f\left(I S_{n-1}\right)\right)$ was constructed; in this case to calculate the dependent variable using preliminary operational data of enterprises for 2020. The characteristics of the constructed models are given in Table. 4.

Table 4: Regression models of the influence of the integrated indicator of the synergetic effect of the economic activity of business network interaction on the profitability of machine-building enterprises in the Kharkiv region

\begin{tabular}{|l|c|c|}
\hline Lag (years) & $\mathrm{L}=0$ & $\mathrm{~L}=1$ \\
\hline & & $\begin{array}{l}R_{n}=0.0194 \times I S_{n}{ }^{2}+ \\
0.4928 \times I S_{n}-0.81\end{array}$ \\
\hline
\end{tabular}

Table 4 shows the most significant F-value, pvalue, $t$-value models of variants of linear and polynomial regression of 1-3 degrees. The constructed models' adequacy is evidenced by the empirical value of the F-value (276.31 and 107.25), which for both constructed models exceeds the tabular value of 3.40 with the number of degrees of freedom $\mathrm{df}=(2 ; 24)$ and the significance level $\alpha=0.05$ and indicator $\mathrm{p}$ value $<0.05$. Empirical values of $t$-value for independent variables modulo exceed table 2.06 at a significance level of $\alpha=0.05$. 
The constructed models demonstrate a statistically significant stimulating effect of the integrated synergy indicator on enterprises' profitability in the current $(\mathrm{L}=0)$ and next $(\mathrm{L}=$ 1) period.

\section{DISCUSSION}

In this research, the proposed methodological approach identified the most important and significant qualitative characteristics of the enterprise's synergistic effect of economic activity within the network interaction as a form of business organization. The proposed methods for assessing the qualitative parameters of network interaction's synergistic effect (Fiorentino \& Garzella, 2015; Zhang et al., 2018) do not indicate the sources of the synergistic effect. But they also did not make it possible to compare the actual effect of economic activity of the enterprise with the potential with maximum efficiency of network management.

The selection of potential business partners for interaction and formation within the structure of the business network is based on the consistency of goals, objectives, and existing problems of the entire business network and operating business units, as well as appropriateness, based on the internal and external environment. has a direct impact on the business partners of the network and determines the trend of its development (Abbas et al., 2019; Chen, Lei \& Hsu, 2019). Therefore, a qualitative approach should include an expert assessment of management (employees of enterprises, external experts) regarding the presence or absence of a synergistic effect and it is scoring. This approach allows the separation of the synergy efficiency from the enterprise's overall efficiency, not related to network interaction, to comprehensively assess the synergy effect or based on priority areas, depending on the study's objectives.

The econometric approach of synergetic effect assessment developed from the limits of our research from the methodological point of view of monitoring of expediency of business network interaction allows us to:

- Quantify the level of synergy (based on the values of the components of the synergetic effect of economic activity within the business network interaction and deviations of their actual values from potential);

- Identify weaknesses in managing the network structure and interaction between its members that need to be eliminated (and strengths are the key to efficiency) to establish the feasibility of a business network interaction partnership under the influence of environmental factors at this stage of business development for the entire network and at the level of an individual network partner.

Characterize the influence of economic activity's synergetic effect as a quantitative parameter on the enterprise's efficiency, expressed in terms of profitability. This, in turn, provides an opportunity to constantly monitor the enterprise's economic activity as a partner of the entrepreneurial network structure, carry out a prognostic assessment of competitiveness and determine strategic directions of development.

But it should be noted that in assessing the impact of the synergistic effect of economic activity on business network interaction, machine-building enterprises were studied, reflecting the specifics of activity and network interaction only in this sector of the economy. Therefore, the results obtained in this study can be extended only to this industry. But along with this, the proposed approach to monitoring is a universal technique. It can be used for any business network, regardless of the type of economic activity, the scale of economic activity, and the number of network partners. The only difference will be the system of qualitative parameters of the synergetic effect of economic activity.

\section{CONCLUSION}

Based on the study, it was found that most enterprises of the machine-building industry of Ukraine are characterized mainly by a medium and low level of the synergistic effect of economic activity in terms of the network interaction of enterprises. It was determined that the increase of qualitative parameters of the effectiveness of network interaction management directly proportionally affects the 
level of synergetic effect of economic activity of enterprises. But in modern business conditions, the factors that reduce network interaction's effectiveness are the insufficient level of innovation in the management of labor potential and inefficiency in the management of environmental and social components of economic activity of enterprises. This indicates that a more significant impact of the synergistic effect, which arises due to the effective management of network interaction, on the profitability of enterprises is manifested in the long run.

\section{REFERENCES}

Abbas, J., Raza, S., Nurunnabi, M., Minai, M.S., \& Bano, S. (2019). The Impact of Entrepreneurial Business Networks on Firms' Performance Through a Mediating Role of Dynamic Capabilities. Sustainability, 11, 3006. https://doi.org/10.3390/su11113006

Adam, M., Assimakis, N., \& Farina, A. (2015). Golden section, Fibonacci sequence and the time invariant Kalman and Lainiotis filters. Applied Mathematics and Computation, 250, 817-831. https://doi.org/10.1016/j.amc.2014.11.022

Chen, Y.-S., Lei, H.-S., \& Hsu, W.-C. (2019). A Study on the Sustainable Development Strategy of Firms: Niche and Social Network Theory. Sustainability, 11, 2593. https://doi.org/10.3390/su11092593

Fang, X., Ji, Z., Chen, Z., Chen, W., Cao, C., \& Gan, J. (2020). Synergy Degree Evaluation of Container Multimodal Transport System. Sustainability, 12, 1487. https://doi.org/10.3390/su12041487

Fiorentino, R. \& Garzella, S. (2015). Synergy management pitfalls in mergers and acquisitions. Management Decision, 53(7), 1469-1503. https://doi.org/10.1108/MD-122014-0692

Hair, J. F., Hult, G. M., Ringle, C. M., \& Sarstedt, M. (2017). A primer on partial least squares structural equation modeling (PLS-SEM). Thousand Oaks, CA: Sage Publications.

Khurana, S., Haleem, A., Luthra, S., \& Mannan, B. (2021). Evaluating critical factors to implement sustainable oriented innovation practices: An analysis of micro, small, and medium manufacturing enterprises. Journal of Cleaner Production, 285, 125377. https://doi.org/10.1016/j.jclepro.2020.125377

Lipovetsky, S. (2017). Factor analysis by limited scales: which factors to analyze? Journal of Modern Applied Statistical Methods, 16(1), 233-245. https://doi.org/10.22237/jmasm/1493597520

Mainali, B., Luukkanen, J., Silveira, S., \& Kaivooja, J. (2018). Evaluating Synergies and Trade-Offs among Sustainable Development Goals (SDGs): Explorative Analyses of Development Paths in South Asia and SubSaharan Africa. Sustainability, 10, 3, 815. https://doi.org/10.3390/su10030815

Megits, N., Neskorodieva, I., \& Schuster, J. (2020). Impact assessment of the COVID19 on trade between Eastern Europe and China. Journal of Eastern European and Central Asian Research (JEECAR), 7(3), 385-399. https://doi.org/10.15549/jeecar.v7i3.579

Menke, W. (2018). Factor Analysis. Geophysical Data Analysis (Fourth Edition). New York: Academic Press, 207-222.

National Science Foundation. (2018). Science and Engineering Indicators 2018. Retrieved January 18, 2021, from https://www.nsf.gov/statistics/2018/nsb201 81/report/sections/industry-technologyand-the-global-marketplace/patterns-andtrends-of-knowledge--and-technologyintensive-industries

On urgent measures for reforms and strengthening the state. (2019). Decree of the President of Ukraine on November 8, 2019 N837/2019. https://zakon.rada.gov.ua/laws/show/837/2 019?lang=en\#Text

Questionnaire to determine the qualitative components of the synergistic effect of economic activity of enterprises for business interaction networks. (2019). https://docs.google.com/forms/d/13FsWYZd On7EqZVg1e04aNyVwFhHOutgGYYg0euG1vk/viewfor m?edit_requested=true

Rzepka, A. (2017). Inter-organizational Relations as a One of Sources of Competitive Advantage 
of Contemporary Enterprises in the Era of Globalization. Procedia Engineering, 174, 161-170. https://doi.org/10.1016/j.proeng.2017.01.195

Shtal, T., Hurzhii, N., \& Bresciani, S. (2016). Integrational Interaction Synergy Effects in Export Distributional Channels of Enterprise. British Journal of Economics, Management \& Trade, 12(2), 1-10. https://doi.org/10.9734/BJEMT/2016/20708

Szromek, A.R. (2020). Model of Business Relations in Spa Tourism Enterprises and Their Business Environment. Sustainability, $12,4941$. https://doi.org/10.3390/su12124941

The World Bank. (2020). Doing Business 2020. http://documents1.worldbank.org/curated/e n/688761571934946384/pdf/DoingBusiness-2020-Comparing-BusinessRegulation-in-190-Economies.pdf

Zadorozhna, L. (2014). Forming Agroindustries Clusters for Reaching Competitiveness of Ukrainian Agroindustrial Sector. Journal of Eastern European and Central Asian Research (JEECAR), 1(1), 11. https://doi.org/10.15549/jeecar.v1i1.26

Zhang, D., Sun, X., Liu, Y., Zhou, S., \& Zhang, H. (2018). The Effects of Integrative Leadership on the Enterprise Synergy Innovation Performance in a Supply Chain Cooperative Network. Sustainability, 10, 2342. https://doi.org/10.3390/su10072342

\section{ABOUT THE AUTHORS}

Valeriia Dykan, email: valeriya.prof2015@gmail.com

Dr. Valeriia Dykan is a Full Professor of Department of Management and Administration of Karazin Business School, V. N. Karazin Kharkiv National University, Ukraine.

Mr. Oleksandr Pakharenko is a Graduate Student of Department of Management and Administration of Karazin Business School, V. N. Karazin Kharkiv National University, Ukraine.

Dr. Volodymyr Saienko is a Professor of the Academy of Management and Administration, Opole, Poland.

Mr. Andrii Skomorovskyi is an Assistant of the Academy of Management and Administration, Opole, Poland

Dr. Tetiana Neskuba is an Associate Professor of Department of Marketing, Commercial Activity and Economic Theory of Ukrainian State University of Railway Transport, Ukraine. 